\title{
A CRIMINALIDADE NO RIO GRANDE DO SUL: UM ESTUDO SOBRE OS TIPOS DE CRIME E ASPECTOS DO DESENVOLVIMENTO REGIONAL NO PERÍODO DE 2007 A 2010
}

\section{CRIME IN RIO GRANDE DO SUL: A STUDY ON THE TYPES OF CRIME AND ASPECTS OF REGIONAL DEVELOPMENT IN THE PERIOD 2007 TO 2010}

\section{Nelson Guilherme Machado Pinto}

Programa de Pós-Graduação em Administração - Universidade Federal de Santa Maria -

UFSM - RS

nelguimachado@hotmail.com

Daniel Arruda Coronel

Programa de Pós-Graduação em Administração - Universidade Federal de Santa Maria -

UFSM - RS

daniel.coronel@uol.com.br

Reisoli Bender Filho

Programa de Pós-Graduação em Administração - Universidade Federal de Santa Maria -

UFSM - RS

reisolibender@yahoo.com.br

Submissão: $23 / 01 / 2015$

Aprovação: 08/09/2016 


\section{RESUMO}

A criminalidade é um problema com impactos nas diversas esferas da sociedade. Além disso, há uma dificuldade em trabalhar com dados empíricos relacionados a essa temática devido à dificuldade de coletar informações sobre esses aspectos. Diante desse contexto, o objetivo do trabalho consiste em verificar os impactos do desenvolvimento regional sobre os tipos de crimes praticados no Rio Grande do Sul, considerando o período de 2007 a 2010. Especificamente, buscou-se verificar se há diferenças locais nas regiões gaúchas entre os tipos de crimes praticados: contra o patrimônio e contra pessoa. Para isso, foram desenvolvidos dois modelos analíticos, baseados em painel; o primeiro, para verificar os impactos de aspectos regionais sobre os crimes contra patrimônio e o segundo, contra a pessoa. Foram adicionadas variáveis dummies, com a finalidade de verificar diferenças regionais quanto à criminalidade nas três macrorregiões do estado: Norte, Nordeste e Sul. Os resultados indicaram que a renda mostrou-se como um dos fatores potencializadores do crime, enquanto que melhores condições de saúde tendem a reduzir a prática de atos criminosos. Em termos geográficos, a maior incidência de crimes foi constatada na região Nordeste, região com características diferenciadas de desenvolvimento local.

Palavras-chave: desenvolvimento regional; criminalidade; Rio Grande do Sul. 


\begin{abstract}
Crime is a problem with impacts on different spheres of society. In addition, there is a difficulty in working with empirical data related to this issue because of the difficulty of collecting information on these aspects. In this context, the aim of this work is to verify the impact of regional development on the types of crimes committed in Rio Grande do Sul, considering the period from 2007 to 2010. Specifically, tried to determine whether there are local differences in regions of Rio Grande do Sul between the types of crimes practiced: against property and against person. For this, two analytical models have been developed based on the panel; the first, to verify the impacts of regional aspects of the crimes against property and the second against the person. Dummy variables were added, in order to verify regional differences in crime in the three geographical regions of the state: North, Northeast and South. The results indicated that income was shown as one of the potential factors of crime, while better health tend to reduce the practice of criminal acts. Geographically, the highest incidence of crime was found in the Northeast, the region with distinctive characteristics of local development.
\end{abstract}

Keywords: regional development; crime; Rio Grande do Sul. 


\section{INTRODUÇÃO}

O ser humano possui a sua vida marcada por escolhas. De maneira geral, essas decisões são tomadas de forma racional, sendo que o indivíduo pondera os benefícios e os custos relacionados a cada uma de suas decisões. Assim, questões profissionais e pessoais do indivíduo são tomadas de acordo com a sua racionalidade e a relação que ele possui com o ambiente.

Entretanto, em determinados contextos, os indivíduos não conseguem atingir os seus objetivos por meio do setor legal da economia. Em decorrência dessa situação, o mesmo pensamento racional do indivíduo pode determinar a escolha pela ilegalidade mensurando os custos e os benefícios por optar pelo setor ilegal, levando, consequentemente, à criminalidade (BECKER, 1968).

Diante desse contexto, o crime é uma atividade considerada das mais antigas da humanidade. Ela pode ser entendida como um mecanismo de distribuição de riqueza ou então como um fardo econômico e social. Contudo, no decorrer de sua evolução, a sociedade procurou combater a criminalidade com diferentes formas de punição (GORDON et al., 2009).

A criminalidade é um problema presente na sociedade com consequências sobre o bem-estar social, pois aumenta os gastos públicos e privados com segurança, diminui a qualidade de vida e de estoque de capital humano como também reduz as atividades relacionadas a investimentos e turismo de uma determinada região. Dessa forma, o problema do crime causa preocupação nas questões de desenvolvimento de uma localidade (SOARES; ZABOT; RIBEIRO, 2011).

De uma forma geral, os crimes são agrupados em dois grandes grupos. Existem aqueles com fins estritamente econômicos, que podem ser denominados crimes contra o patrimônio. Ademais, existem crimes que partem de motivações pessoais dos seus agentes e são denominados como crimes contra a pessoa. Esses crimes tendem a estarem mais presentes em áreas menos desenvolvidas economicamente e os crimes contra o patrimônio tendem a serem mais recorrentes em regiões onde os indivíduos possuem maior poder aquisitivo (BATELLA; DINIZ, 2010).

Além disso, nota-se que muitos dos aspectos ligados à criminalidade possuem relação com o desenvolvimento regional. Isso porque, conforme afirmam Batella e Diniz (2010), variáveis como riqueza, desigualdade de renda, infraestrutura, educação e estrutura 
populacional possuem impactos na ocorrência de atos criminosos. Corroborando essa ideia, nota-se que a criminalidade é um fenômeno local, visto que diferentes cidades dentro de uma mesma unidade federativa podem apresentar diferentes níveis de criminalidade. A ocorrência dessa situação é decorrente dos diferentes níveis de desenvolvimento econômico, social e cultural que as cidades apresentam entre si (OLIVEIRA, 2005).

Faz parte do senso comum creditar a resolução de problemas socioeconômicos de uma região como solução para os problemas da violência. Dessa forma, apesar de haver um relacionamento bilateral entre criminalidade e desenvolvimento, existem evidências de que os fatores socioeconômicos são causadores da criminalidade. Além disso, acredita-se que, na medida em que os indicadores de desenvolvimento aumentem, a incidência de crimes tende a diminuir (SHIKIDA; OLIVEIRA, 2012).

Ademais, há necessidade de destacar os aspectos emocionais e da racionalidade limitada que fazem parte dos aspectos relacionados a criminalidade. As premissas relacionadas à racionalidade plena começam a ser contestadas sendo que os indivíduos não são totalmente racionais, mas racionalmente limitados. Os indivíduos nem sempre maximizam, nem possuem a capacidade necessária para conhecer e avaliar todas as alternativas existentes em qualquer tomada de decisão. Os decisores pretendem ser racionais, e provavelmente os seus comportamentos sejam razoáveis e não irracionais, porém estão sujeitos a limitações em um processo complexo (SIMON, 1965).

Afora isso, questões relacionadas aos agentes envolvidos no combate à criminalidade consistem em um ponto a ser explorado. Isso porque a exploração das relações entre os aspectos que são ineficientes em determinados setores da sociedade demonstram-se como um primeiro passo no combate à criminalidade (SCALCO; AMORIN; GOMES, 2012).

Dessa forma, verificar aspectos da criminalidade demonstra-se como um tema de relevância na sociedade brasileira, se comparado a outras partes do mundo, visto que os índices de criminalidade no país são até cinco vezes superiores comparativamente aos dos países europeus (OLIVEIRA, 2008). Além disso, dados apontam que o Brasil estava, no ano de 2014, como décimo primeiro país menos seguro do mundo dentro de uma lista de cento e trinta e dois países (PROGRESSO SOCIAL, 2014).

Por sua vez, não diferente desse contexto de violência, está a realidade do estado do Rio Grande do Sul, pois, apesar de apresentar taxas de homicídios menores que a média nacional, os furtos e os roubos possuem médias superiores ao resto do país. De certa forma, 
essa conjuntura do estado justifica que a criminalidade seja um dos temas mais discutidos em campanhas e em meios de comunicação (OLIVEIRA, 2008).

Apesar da preocupação política e social, ainda são escassos os trabalhos que tratam sobre o tema. Dentre as principais causas para essa situação está a dificuldade de encontrar estatísticas disponíveis com padronização e confiabilidade. Além disso, a criminalidade demonstra-se como um tema complexo que envolve as mais variadas áreas de conhecimento (OLIVEIRA, 2008), de modo que alguns estudos dentro das ciências sociais procuram retratar aspectos relacionados à criminalidade. Dentre esses podem ser citados os de Batella, Diniz e Teixeira (2008), Farias, Figueiredo e Lima (2008), Oliveira (2008), Oliveira e Marques Júnior (2009), Batella e Diniz (2010), Nascimento et al. (2011), Resende e Andrade (2011), Soares, Zabot e Ribeiro (2011), Scalco, Amorin e Gomes (2012) e Shikida e Oliveira (2012).

Além disso, diante da discussão acerca das evidências empíricas em estudos referentes à criminalidade, um dos grandes problemas dos trabalhos, principalmente no Brasil, refere-se a não notificação dos crimes. Assim, grande parte dos atos criminosos não é registrada, acarretando em perda de dados estatísticos e comprometendo, consequentemente, a análise das evidências empíricas (VIAPIANA, 2006).

Neste sentido, a fim de contribuir com os estudos de criminalidade no contexto gaúcho, explorando os aspectos locais da criminalidade bem como suas relações com o desenvolvimento e propensão ao crime, o objetivo do presente trabalho consistiu em verificar os impactos que questões de desenvolvimento regional possuem nos tipos de crimes praticados no Rio Grande do Sul, no período de 2007 a 2010. Especificamente, pretendeu-se verificar se há diferenças locais nas regiões gaúchas quando considerados os tipos de crimes praticados no Rio Grande do Sul no referido período. Dessa forma, o estudo avança em relação aos demais na medida em que relaciona aspectos da criminalidade com questões de desenvolvimento, além de verificar se a localidade influencia nas práticas criminosas.

É pertinente destacar que as teorias relacionadas remontam a determinados aspectos, os quais englobam um conjunto de áreas das ciências sociais a fim de discutir e ampliar o conhecimento relacionado ao tema. Entretanto, essas diferentes abordagens estudam em geral quatro elementos presentes ao ato criminoso, sendo eles a lei, o criminoso, o alvo e o lugar (SILVA, 2004). Aqui, por se verificar os aspectos da criminalidade e seus diferentes impactos em determinadas localidades, o foco é dado ao último elemento, o lugar.

Com a finalidade de atingir os objetivos, o presente texto está estruturado, além desta introdução, em outras quatro seções. Na segunda, é apresentado o referencial teórico; na seção 
seguinte, os procedimentos metodológicos; na quarta seção, os resultados são analisados e discutidos e, por último, são apresentadas as considerações finais acerca da temática.

\section{REFERENCIAL TEÓRICO}

O padrão de criminalidade de uma região está ligado às características regionais, tais como localidade e concentração de riqueza. Além disso, o tamanho da cidade pode ser um fator explicativo para as atividades criminosas. Assim, a criminalidade possui maior ocorrência nas grandes cidades devido ao maior retorno que o crime proporciona, sua menor probabilidade de punição e menores custos relacionados ao crime (OLIVEIRA, 2005; BATTELA; DINIZ, 2010).

Existem três vertentes que buscam explicar a origem e expansão dos aspectos relacionados ao crime. A primeira delas, de origem marxista, preconiza que o aumento da criminalidade está vinculado às características do processo capitalista cada vez mais concorrencial, principalmente aqueles crimes classificados como lucrativos. A segunda vertente afirma que o aumento da criminalidade possui associação com problemas estruturais e conjunturais da sociedade, tais como alto desemprego, alta concentração de renda, baixos níveis de escolaridade e problemas em atividades de policiamento e justiça. Por fim, a última reconhece que os crimes nada mais são do que um setor ou atividade da economia, assim como outra atividade econômica tradicional qualquer (PEREIRA; FERNANDEZ, 2000).

Ademais, os crimes praticados podem ser comumente classificados em uma perspectiva dual, considerando os crimes que envolvem aspectos econômicos e os que não ocorrem motivados por esse aspecto. O tratamento do crime a partir de uma perspectiva econômica teve seu primeiro enfoque mais relevante em Becker (1968). Para o autor, a motivação econômica para a realização de um crime ocorre pela escolha racional de um indivíduo em mensurar os benefícios e os custos entre o setor legal e ilegal, considerando o setor ilegal como mais vantajoso.

Neste trabalho, optou-se pela classificação da criminalidade pelos aspectos quanto ao patrimônio e quanto à pessoa. No caso do primeiro, existem interesses financeiros ou relacionados a algum bem que são de propriedades dos agentes que sofrem o crime. Já os crimes contra a pessoa são caracterizados como os que não possuem as mesmas motivações, afetando apenas aspectos não econômicos dos indivíduos como a sua integridade física e moral. 
A criminalidade possui uma série de condicionantes que levam o indivíduo desde a elaboração à execução de fato do ato criminoso. Para Batella e Diniz (2010), algumas dessas condicionantes se relacionam ao desenvolvimento humano, ao grau de riqueza, ao nível de desigualdade de renda, às questões de infraestrutura, aos aspectos educacionais, à estrutura populacional e às questões referentes à imigração.

O principal condicionante relacionado ao desenvolvimento humano está no fato de que certas regiões possuem melhores condições econômicas do que outras. Além disso, grandes concentrações populacionais levam, de certa forma, a um enfraquecimento dos mecanismos de controle da sociedade e, consequentemente, favorecem uma maior propensão à ocorrência de atos criminosos. Ademais, o aspecto de riqueza das regiões acaba gerando mais oportunidades para as ações criminosas, visto que há a existência de alvos mais compensadores (BEATO FILHO, 1998).

A desigualdade de renda é outra condicionante da criminalidade por aproximar realidades muito distantes. Dessa forma, principalmente nas grandes cidades onde riqueza e pobreza são realidades muito próximas, há um desencadeamento de atos criminosos em uma maior frequência se comparada a regiões onde essa distância é maior (BRICEÑO-LEÓN, 2002). Já o aspecto da infraestrutura está muito ligado ao problema da moradia, no qual a exclusão territorial e as más condições de moradia levam ao conflito e à violência urbana (ROLNIK, 1999).

Quanto ao aspecto educacional, tem-se uma correlação negativa com a criminalidade, visto que regiões com baixos níveis de escolaridade podem vir a possuir atividade criminal praticada de forma mais constante. Isso ocorre principalmente em função da falta de conscientização da população por falta de escolaridade, praticando, consequentemente, o ato criminoso, ou pela falta de oportunidades no mercado de trabalho pelos baixos níveis educacionais, tendo assim o crime como uma das saídas (BATELLA; DINIZ, 2010). Por último, a estrutura populacional e a imigração estão relacionadas ao tamanho e às oportunidades geradas aos indivíduos, as quais, não ocorrendo, tornam-se aspectos desencadeadores de crimes, principalmente, contra o patrimônio (BEATO FILHO, 1998).

Além disso, uma dentre as tantas causas da criminalidade é o que se denomina como patologia individual, sendo caracterizada pelo fato de indicar que algumas pessoas com determinados aspectos genéticos ou adquiridos no decorrer do tempo são mais propensas a cometer crimes em relação a outros indivíduos sem tais características. Dessa forma, por meio 
dessa linha de discussão, o indivíduo nasce para ser criminoso (BARCELLOS; PEREZ, 2009).

A partir das questões levantadas acerca da criminalidade, conforme Quadro 1, alguns estudos procuraram determinar aspectos relacionados à criminalidade.

\section{Quadro 1 - Estudos empíricos de criminalidade}

\begin{tabular}{|c|c|c|c|}
\hline Região do Estudo & Método Utilizado & Principais Resultados & Referência \\
\hline $\begin{array}{l}\text { Cidades Médias de } \\
\text { Minas Gerais }\end{array}$ & $\begin{array}{l}\text { Análises } \\
\text { descritivas, de } \\
\text { mapeamento e } \\
\text { modelo } \\
\text { econométrico }\end{array}$ & $\begin{array}{l}\text { Houve um aumento substancial da criminalidade } \\
\text { violenta desde } 1995 \text {, principalmente nos crimes } \\
\text { ligados ao patrimônio dentro da análise realizada em } \\
\text { Minas Gerais, no período analisado. }\end{array}$ & $\begin{array}{l}\text { Batella, Diniz } \\
\text { e Teixeira } \\
(2008)\end{array}$ \\
\hline $\begin{array}{l}\text { Municípios } \\
\text { Minas Gerais }\end{array}$ & $\begin{array}{l}\text { Metodologia de } \\
\text { índices e análise } \\
\text { de cluster }\end{array}$ & $\begin{array}{l}\text { Existem sete grupos distintos de municípios no } \\
\text { estado mineiro, conforme o nível de criminalidade e } \\
\text { os diferentes crimes praticados. Dessa forma, deve } \\
\text { haver diferentes políticas de combate à criminalidade } \\
\text { conforme as necessidades de cada local. }\end{array}$ & $\begin{array}{l}\text { Farias, } \\
\text { Figueiredo e } \\
\text { Lima (2008) }\end{array}$ \\
\hline $\begin{array}{l}\text { Municípios do Rio } \\
\text { Grande do Sul }\end{array}$ & étrico & $\begin{array}{l}\text { A desigualdade de renda e as aglomerações urbanas } \\
\text { são fatores que potencializam a criminalidade em } \\
\text { cidades gaúchas. Além disso, fica evidenciado que os } \\
\text { problemas na estrutura familiar e a ineficiência do } \\
\text { ensino no estado afetam positivamente a } \\
\text { criminalidade. }\end{array}$ & $\begin{array}{l}\text { Oliveira } \\
(2008)\end{array}$ \\
\hline $\begin{array}{lr}\text { Região } & \text { Corede } \\
\text { Produção do Rio } \\
\text { Grande do Sul }\end{array}$ & nétrico & $\begin{array}{l}\text { Os fatores renda e aglomeração urbana são os } \\
\text { principais determinantes da criminalidade para o caso } \\
\text { estudado. }\end{array}$ & $\begin{array}{l}\text { Oliveira e } \\
\text { Marques } \\
\text { Júnior (2009) }\end{array}$ \\
\hline $\begin{array}{ll}\text { Municípios } & \text { de } \\
\text { Minas Gerais } & \end{array}$ & $\begin{array}{l}\text { Técnicas de } \\
\text { mapeamento, } \\
\text { análise fatorial e } \\
\text { correlação }\end{array}$ & $\begin{array}{l}\text { Os crimes contra pessoas tendem a serem mais } \\
\text { presentes em áreas menos desenvolvidas } \\
\text { economicamente e os crimes contra patrimônio } \\
\text { tendem a serem mais recorrentes em regiões onde os } \\
\text { indivíduos possuem maior poder aquisitivo. }\end{array}$ & $\begin{array}{l}\text { Batella e } \\
\text { Diniz (2010) }\end{array}$ \\
\hline $\begin{array}{l}\text { Município } \\
\text { Aracaju - SE }\end{array}$ & nétrico & $\begin{array}{l}\text { A relação entre jovens mostrou-se como a mais } \\
\text { importante na explicação das taxas de homicídio na } \\
\text { capital sergipana. }\end{array}$ & $\begin{array}{l}\text { Nascimento } \\
\text { et al. (2011) }\end{array}$ \\
\hline $\begin{array}{l}\text { Cidades Brasileiras } \\
\text { com mais de cem } \\
\text { mil habitantes }\end{array}$ & econ & $\begin{array}{l}\text { A desigualdade de renda apresenta correlação } \\
\text { positiva e robusta principalmente com os crimes } \\
\text { contra o patrimônio, assumindo papel de suma } \\
\text { importância dentro da realidade nacional, } \\
\text { demonstrando ser uma das determinantes da } \\
\text { criminalidade que mais causam perdas substanciais } \\
\text { de bem-estar social. }\end{array}$ & $\begin{array}{l}\text { Resende } \\
\text { Andrade } \\
(2011)\end{array}$ \\
\hline $\begin{array}{ll}\text { Municípios } & \text { de } \\
\text { Santa Catarina } & \end{array}$ & $\begin{array}{l}\text { Metodologia de } \\
\text { índices e Análise } \\
\text { Envoltória de } \\
\text { Dados }\end{array}$ & $\begin{array}{l}\text { Os municípios mais eficientes com relação aos gastos } \\
\text { públicos, em sua maioria, obtiveram os menores } \\
\text { indicadores criminológicos. }\end{array}$ & $\begin{array}{l}\text { Soares, Zabot } \\
\text { e Ribeiro } \\
(2011)\end{array}$ \\
\hline $\begin{array}{l}\text { Municípios } \\
\text { Minas Gerais }\end{array}$ & $\begin{array}{l}\text { Análise } \\
\text { Envoltória de } \\
\text { Dados e modelo } \\
\text { econométrico }\end{array}$ & $\begin{array}{l}\text { Existem diferenças entre a eficiência dos municípios, } \\
\text { evidenciando municípios que são referências em } \\
\text { segurança pública no estado, devendo ser utilizados } \\
\text { como exemplo pelos municípios menos eficientes. }\end{array}$ & $\begin{array}{l}\text { Scalco, } \\
\text { Amorin } \\
\text { Gomes } \\
(2012) \\
\end{array}$ \\
\hline $\begin{array}{lr}\text { Municípios } & \text { da } \\
\text { Mesorregião } & \text { Oeste } \\
\text { do Paraná } & \\
\end{array}$ & $\begin{array}{l}\text { Análise } \\
\text { correlação }\end{array}$ & $\begin{array}{l}\text { Há uma correlação negativa entre os objetos } \\
\text { estudados, evidenciando que os crimes violentos } \\
\text { tendem a cair com o aumento do desenvolvimento. }\end{array}$ & $\begin{array}{l}\text { Shikida } \\
\text { Oliveira } \\
(2012)\end{array}$ \\
\hline
\end{tabular}

Fonte: Elaborado pelos autores. 
Apesar de algumas regiões necessitarem de atenção imediata quanto a políticas públicas para redução da criminalidade, o tratamento isolado de regiões quanto ao tema mostra-se insuficiente. Conforme Oliveira (2008), isso se dá porque as políticas públicas devem ser globais, visto que, como a vizinhança é relevante, uma política pública adotada em apenas uma cidade não reduziria a criminalidade se as cidades vizinhas não adotassem políticas públicas semelhantes.

\section{METODOLOGIA}

Para alcançar os objetivos estabelecidos, foi utilizada a modelagem em painel, sendo desenvolvidos dois modelos analíticos. O primeiro buscou verificar os impactos dos aspectos regionais nos crimes contra o patrimônio e o segundo procurou avaliar os impactos do desenvolvimento regional nos crimes contra a pessoa. A estimação de ambos os modelos teve como finalidade comparar as influências dos dois tipos de crimes. Ademais, foram adicionadas variáveis dummies com a finalidade de verificar possíveis diferenças regionais quanto à criminalidade nas três macrorregiões do Rio Grande do Sul.

\subsection{Dados em Painel}

A tipologia de dados em painel consiste em observações de $n$ entidades ou objetos de análise para dois ou mais períodos de tempo, combinando as dimensões de séries temporais e corte transversal. Uma das vantagens na utilização de dados em painel consiste em proporcionar mais eficiência e graus de liberdade para análise, captando aspectos que não são visualizados quando é feito outro tipo de análise (GREENE, 2008). Conforme Baltagi (2005), a equação geral de regressões em painel é expressa da seguinte forma:

$y_{i t}=\alpha+X_{i t}^{r} \beta+\mu_{i t}, \mathrm{i}=1, \ldots, \mathrm{N} ; \mathrm{t}=1, \ldots, \mathrm{T}$

em que: $i$ denota unidades de medidas pesquisadas como indivíduos, empresas e países; $t$ representa o período de tempo; $\alpha$ o efeito individual específico; $\beta$ o coeficiente angular; $X_{i t}^{*}$ a matriz de variáveis regressores da unidade $i$ no período de tempo $t, \mathrm{e} ; \mu$ representa o termo de erro aleatório. 
Considerando os modelos de painel, os mais utilizados são os de Efeitos Fixos (EF) e os de Efeitos Aleatórios (EA). Particularmente, o modelo de EF considera o fato de que pode haver correlações entre o intercepto e as variáveis explicativas em qualquer período de tempo. Já o modelo de EA possui as mesmas suposições do modelo de EF, variando apenas no tratamento do intercepto, que passa a ser tratado como variável aleatória e não mais como um parâmetro fixo (BALTAGI, 2005; GREENE, 2008). Entretanto, a utilização destes modelos acaba tornando-se excludente e, conforme as características dos dados, um modelo terá sua utilização mais recomendada.

Portanto, uma forma de decidir entre qual modelo utilizar está na comparação de ambos, verificando se existe correlação entre os fatores não observados e as variáveis explicativas a partir da aplicação do teste de Hausman. Este teste analisa se a diferença entre os coeficientes dos EF e EA não é sistemática. Além disso, o método de EA acaba consumindo muitos graus de liberdade, existindo a necessidade de haver número de períodos superiores ao número de coeficientes da regressão e, quando não é possível fazer a estimação por meio desse empecilho, deve-se utilizar EF (GREENE, 2008). Aqui ocorre a última situação, sendo que existem seis coeficientes de regressão e quatro períodos de análise. Portanto, a estimação é feita por meio do modelo de Efeitos Fixos.

A fim de testar os pressupostos dos modelos, com intuito de não gerar resultados enviesados, foram realizados testes econométricos. Para verificar a presença de heterocedasticidade, no caso de os termos de erro possuírem variâncias divergentes, foi realizado o teste de Wald. Para a verificação de autocorrelação, foi utilizado o teste de Woodridge.

Quanto à característica dos dados, o modelo de painel é do tipo balanceado quando os dados estão disponíveis para todas as unidades de corte transversal em todos os períodos de tempo (GREENE, 2008). Por meio do estabelecimento da relação entre criminalidade e desenvolvimento regional, ou seja, que questões do desenvolvimento influenciam na criminalidade, os modelos buscam verificar como os crimes contra o patrimônio e contra a pessoa são impactados por aspectos do desenvolvimento regional do Rio Grande do Sul.

Para isso, utiliza-se o somatório de crimes contra o patrimônio e o somatório de crimes contra a pessoa como proxy para esses crimes, respectivamente. Além disso, os aspectos relacionados ao desenvolvimento, por possuírem, de acordo com Todaro e Smith (2009), característica multidimensional, devem ser captados por mais de um aspecto. A partir disso, utilizou-se como proxy para os diferentes aspectos do desenvolvimento os blocos educação, 
renda e saúde do Índice de Desenvolvimento Socioeconômico (Idese), desenvolvido pela Fundação de Economia e Estatística (FEE) do Rio Grande do Sul (FEE, 2014a, b).

Quanto à forma dos dados, foram transformados em logaritmo natural a fim de serem verificadas diretamente as elasticidades das relações. Ademais, pelo fato de a criminalidade demonstrar-se como um fenômeno local, visto que diferentes cidades dentro de uma mesma unidade federativa podem possuir diferentes níveis de criminalidade, foram utilizadas dummies. Essas procuram evidenciar as diferenças entre os tipos de crime nas regiões do Rio Grande do Sul, sendo que foram criadas dummies, correspondentes às três macrorregiões gaúchas: Norte, Nordeste e Sul.

Diante de tais definições, a relação a ser estudada pode ser verificada formalmente a partir das equações em (2) e (3):

$$
\begin{aligned}
& \text { cripatri }_{i k}=\alpha+\beta_{1} \ln D e_{i k}+\beta_{2} \ln D r_{i k}+\beta_{3} \ln D s_{i k}+\beta_{4} D 1_{i k}+\beta_{5} D 2_{i k}+\mu_{i t} \\
& \text { cripess }_{i k}=\alpha+\beta_{1} \ln D e_{i k}+\beta_{2} \ln D r_{i k}+\beta_{3} \ln D s_{i k}+\beta_{4} D 1_{i k}+\beta_{5} D 2_{i k}+\mu_{i t}
\end{aligned}
$$

em que: cripatri $_{i k}$ são os crimes contra o patrimônio do k-ésimo município para o $i$-ésimo período de tempo; cripess $_{i k}$ são os crimes contra a pessoa do $k$-ésimo município para o $i$ ésimo período de tempo; $D e_{i k}$ é o desenvolvimento do bloco educação do Idese do $k$-ésimo município para o $i$-ésimo período de tempo; $D r_{i k}$ é o desenvolvimento do bloco renda do Idese do k-ésimo município para o i-ésimo período de tempo; $D s_{i k}$ é o desenvolvimento do bloco saúde do Idese do k-ésimo município para o i-ésimo período de tempo; $D 1_{i k}$ é a dummy do k-ésimo município para o i-ésimo período de tempo fazer parte da região Nordeste do Rio Grande do Sul; $D 2_{i k}$ é a dummy do k-ésimo município para o i-ésimo período de tempo fazer parte da região Norte do Rio Grande do Sul; $\alpha$ efeito individual específico; $\beta_{1,2,3,4,5}$ é o coeficiente angular de relação das variáveis da regressão, e; $\mu$ é o termo de erro aleatório.

A partir da análise de tais modelos analíticos, é possível verificar como os tipos de crime são impactados pelos aspectos do desenvolvimento regional do Rio Grande do Sul, bem como se existem diferenças nas macrorregiões do estado. Essas macrorregiões são classificadas com base em aspectos do desenvolvimento e no processo histórico do Rio 
Grande do Sul, sendo denominadas como Nordeste, Norte e Sul (ALONSO, 2003; SILVA; MARION FILHO; CORONEL, 2007).

\subsection{Variáveis e Fonte dos Dados}

O universo de estudo ficou limitado aos 496 municípios do Rio Grande do Sul. O período de análise compreendeu os anos de 2007 a 2010, período mais recente com os dados disponíveis. A partir destas definições, para a construção dos modelos foram utilizadas as variáveis apresentadas no Quadro 2.

\section{Quadro 2 - Variáveis do Estudo}

\begin{tabular}{|c|c|c|}
\hline Bloco Variável & Variável & Descrição \\
\hline \multirow[t]{3}{*}{$\begin{array}{l}\text { Desenvolvimento } \\
\text { regional }\end{array}$} & $\begin{array}{l}\text { Desenvolvimento } \\
\text { Educação }\end{array}$ & $\begin{array}{l}\text { Bloco de educação do Idese que capta aspectos da pré-escola, } \\
\text { ensinos fundamental e médio e escolaridade adulta. }\end{array}$ \\
\hline & Desenvolvimento Renda & $\begin{array}{l}\text { Bloco de renda do Idese que capta aspectos da apropriação de } \\
\text { renda per capita e geração de renda. }\end{array}$ \\
\hline & Desenvolvimento Saúde & $\begin{array}{l}\text { Bloco de saúde do Idese que capta aspectos da saúde materno- } \\
\text { infantil, longevidade e condições gerais de saúde. }\end{array}$ \\
\hline \multirow[t]{6}{*}{$\begin{array}{l}\text { Crimes contra } \\
\text { patrimônio }\end{array}$} & Furtos & $\begin{array}{l}\text { Crime que consiste em subtração de coisa alheia móvel para o } \\
\text { próprio indivíduo ou para outros beneficiados. }\end{array}$ \\
\hline & Roubos & $\begin{array}{l}\text { Crime que consiste em subtração de coisa alheia móvel para o } \\
\text { próprio indivíduo ou para outros beneficiados mediante a } \\
\text { grave ameaça ou violência ao agente envolvido. }\end{array}$ \\
\hline & Extorsão & $\begin{array}{l}\text { Crime que consiste no ato de obrigar alguém por meio de } \\
\text { ameaças e violência a tomar determinado comportamento a } \\
\text { fim de obter vantagem econômica ou recompensa. }\end{array}$ \\
\hline & Estelionato & $\begin{array}{l}\text { Crime que consiste em subtração de coisa alheia móvel para o } \\
\text { próprio indivíduo ou para outros beneficiados mediante a } \\
\text { indução do agente ao erro ou por ato fraudulento. }\end{array}$ \\
\hline & $\begin{array}{l}\text { Delitos relacionados à } \\
\text { corrupção }\end{array}$ & $\begin{array}{l}\text { Crime relacionado a obter vantagem indevida relacionada a } \\
\text { patrimônio público. }\end{array}$ \\
\hline & Entorpecentes - tráfico & $\begin{array}{l}\text { Crime relacionado a possuir ou utilizar substâncias ilegais para } \\
\text { comercialização. }\end{array}$ \\
\hline \multirow[t]{4}{*}{$\begin{array}{l}\text { Crimes contra } \\
\text { pessoa }\end{array}$} & Homicídio doloso & $\begin{array}{l}\text { Crime que ocasiona morte e demonstra intenção do agente em } \\
\text { querer ou assumir o risco de matar alguém. }\end{array}$ \\
\hline & Latrocínio & $\begin{array}{l}\text { Crime de roubo acompanhado de morte antes ou depois do ato } \\
\text { violento. }\end{array}$ \\
\hline & $\begin{array}{l}\text { Delitos relacionados à } \\
\text { armas e munições }\end{array}$ & $\begin{array}{l}\text { Crimes relacionados a aspectos ilegais referentes a armas e } \\
\text { munições. }\end{array}$ \\
\hline & Entorpecentes - posse & Crime relacionado a possuir ou utilizar substâncias ilegais. \\
\hline
\end{tabular}

Fonte: Elaborado pelos autores.

As variáveis de desenvolvimento foram utilizadas como independentes, enquanto que as variáveis de criminalidade destacadas no Quadro 2 foram agrupadas conforme a sua classificação. Portanto, as variáveis classificadas como crimes contra o patrimônio e contra a pessoa foram somadas entre seus grupos a fim de representar o total de cada um dos grupos. Esse somatório compõe a variável dependente em cada um dos dois modelos. 
As informações sobre criminalidade foram coletadas na base de dados da Secretaria de Segurança Pública do Rio Grande do Sul (SSP-RS) e os referentes ao desenvolvimento, na base de dados da Fundação de Economia e Estatística (FEE). Todos os dados apresentam periodicidade anual e correspondem ao período de 2007 a 2010.

\section{ANÁLISE E DISCUSSÃO DOS RESULTADOS}

A apresentação dos resultados seguiu a ordem apresentada, primeiro o modelo 1, o qual está relacionado à relação de desenvolvimento e crimes contra o patrimônio e em seguida, o modelo 2, o qual relaciona desenvolvimento e crimes contra a pessoa. Para tanto, inicialmente são discutidos os testes de diagnóstico e de definição. Quanto ao modelo 1, o qual utilizou crimes contra o patrimônio como variável dependente, a partir do teste de Woodridge, observou-se a presença de autocorrelação e, a partir do teste de Wald, a presença de heterocedasticidade, os quais apresentaram respectivamente valores de significância de 0,23 e 0,08 . O mesmo diagnóstico foi verificado para o modelo 2 , o qual utilizou crimes contra a pessoa como variável dependente e os mesmos texto de verificação, apresentando valores de significância de 0,34 para o teste de Woodridge e 0,12 para o teste de Wald.

Para corrigir esses problemas, as estimações foram obtidas a partir do Método de Newey-West. No que tange à definição dos modelos, ambos foram estimados pelo método de efeitos fixos.

As estimativas obtidas para o modelo 1 demonstraram que os aspectos relacionados à educação e à saúde possuem relação negativa com a incidência de crimes contra o patrimônio, enquanto que a renda possui relação positiva (ver Tabela 1). Entretanto, apenas as variáveis de desenvolvimento relacionadas à renda e à saúde apresentaram significância estatística. Com relação às dummies, observam-se diferenças na incidência de crimes contra o patrimônio apenas com relação à Região Nordeste - dummy 1, a qual foi significativa a 1\%. Vale destacar que o poder explicativo, medido pelo $R^{2}$, foi de $32,57 \%$. 
Tabela 1 - Resultados da estimação da regressão do modelo 1 pelo método de Efeitos Fixos com variável dependente crimes contra o patrimônio no período de 2007 a 2010 para os municípios do Rio Grande do Sul

\begin{tabular}{|c|c|c|c|}
\hline Variável & Coeficiente & Estatística t & Significância \\
\hline constante & 0,0075 & 1,0845 & 0,2782 \\
\hline$D e$ & $-0,0042$ & $-0,8246$ & 0,4097 \\
\hline$D r$ & 0,0640 & 2,0508 & $0,0404 *$ \\
\hline$D s$ & $-0,0563$ & $-3,0781$ & $0,0022 * *$ \\
\hline D1 & 0,0095 & 3,4450 & $0,0005 * *$ \\
\hline \multirow[t]{2}{*}{ D2 } & 0,0011 & 0,4583 & 0,6467 \\
\hline & & \multicolumn{2}{|c|}{$\mathrm{R}^{2}$ ajustado $=0,3257$} \\
\hline
\end{tabular}

Fonte: Elaborado pelos autores.

Nota: Valores com $* *$ e $*$ denotam coeficientes significativos ao nível de $1 \%$ e $5 \%$, respectivamente.

Em relação ao modelo 2, as estimativas obtidas demonstraram que os aspectos relacionados à educação e à saúde possuem relação negativa com a incidência de crimes contra a pessoa, enquanto que a renda possui relação positiva (ver Tabela 2). Contudo, novamente apenas as variáveis de desenvolvimento relacionadas à renda e à saúde apresentaram significância estatística. Com relação às dummies, observam-se, da mesma forma do que foi verificado no modelo 1, que as diferenças na incidência de crimes contra a pessoa ocorrem apenas com relação à Região Nordeste - dummy 1, a qual foi significativa a $1 \%$. Vale destacar que o poder explicativo, medido pelo $R^{2}$, foi de $21,97 \%$.

Tabela 2 - Resultados da estimação da regressão do modelo 2 pelo método de Efeitos Fixos com variável dependente crimes contra a pessoa no período de 2007 a 2010 para os municípios do Rio Grande do Sul

\begin{tabular}{cccc}
\hline Variável & Coeficiente & Estatística t & Significância \\
\hline Constante & 0,0102 & 1,4246 & 0,1544 \\
$D e$ & $-0,0034$ & $-0,7376$ & 0,4608 \\
$D r$ & 0,0634 & 2,0504 & $0,0405^{*}$ \\
$D s$ & $-0,0558$ & $-3,0793$ & $0,0021^{* *}$ \\
$D 1$ & 0,0094 & 3,3898 & $0,0007^{* *}$ \\
$D 2$ & 0,0009 & 0,3815 & 0,7028 \\
\hline
\end{tabular}

Fonte: Elaborado pelos autores.

Nota: Valores com $* * \mathrm{e}^{*}$ denotam coeficientes significativos ao nível de $1 \%$ e $5 \%$, respectivamente.

Referente à renda, encontrou-se relação positiva com relação aos crimes contra a pessoa. Quantitativamente, o aumento de $1 \%$ no nível de renda per capita determina a uma expansão de aproximadamente $6,34 \%$ na quantidade de crimes contra a pessoa. Apesar de sofrer aumento de forma menos intensa do que os crimes contra o patrimônio, que possuem ligação mais direta com a renda, o ato criminoso contra as pessoas também possui associação com aspectos monetários e financeiros (PEREIRA; FERNANDEZ, 2000). 
Já com relação à saúde, verifica-se relação inversa, com diminuição de 5,58\% na quantidade de crimes contra a pessoa quando as condições de saúde melhoram em 1\%. Essa relação corrobora a ideia de que muitos crimes são causados por demandas sociais de saúde (CERQUEIRA; LOBÃO; CARVALHO, 2005). Por último, verifica-se que a região Nordeste possui uma maior incidência de crimes que as demais, nesse caso, referente ao crime contra pessoas, por apresentar as grandes aglomerações urbanas e aspectos relacionados à renda maior que nas demais regiões do Rio Grande do Sul (OLIVEIRA, 2008).

A partir dos resultados, de ambos os modelos, nota-se a influência dos níveis de desenvolvimento na criminalidade. De forma geral, níveis elevados de renda tendem a aumentar os crimes contra o patrimônio e contra as pessoas; igualmente, níveis de desenvolvimento mais levados quanto à saúde tendem a gerar reduções na incidência de crimes. Por outro lado, verifica-se que o nível de educação, um dos aspectos-chave para a superação de muitos problemas sociais, não apresentou significância estatística nos modelos estudados, demonstrando a incidência de problemas para dados desse gênero bem como a possibilidade de utilização de alternativas a fim de captar esses aspectos. Ademais, nota-se que a criminalidade no estado possui certa diferenciação com relação às regiões estudadas, o que corrobora as evidências encontradas.

\section{CONCLUSÕES}

A criminalidade é um problema social que impacta a sociedade em diversos aspectos, ao passo que questões relacionadas ao crime mostram-se de difícil mensuração devido à complexidade do assunto. A partir disso, estabelecer determinadas relações considerando aspectos econômicos, sociais e geográficos com a criminalidade demonstra-se como um passo importante para o maior conhecimento do assunto, haja vista que se encontram estudos em pequeno número.

Dessa forma, procurou-se estudar os tipos de crimes nos municípios do Rio Grande do Sul, no período de 2007 a 2010, quanto à relação com o nível de desenvolvimento. Os resultados permitiram verificar que os aspectos relacionados com a renda demonstram-se como fatores potencializados do crime no estado. Isso porque, principalmente, os crimes contra o patrimônio, são motivados por questões econômicas, financeiras e materiais e, portanto, regiões com maiores níveis de renda tendem a ser mais atrativas para os praticantes de atos criminosos. 
A saúde revelou uma relação inversa com a prática criminosa. Isso se deve ao fato de que, juntamente com questões de educação e moradia, os aspectos relacionados à saúde são potencializadores de atos criminosos quando são menos desenvolvidos, ou seja, pouco investimento nesses itens gera uma maior propensão à realização de crimes. Logo, para o Rio Grande do Sul, os municípios com maiores níveis de desenvolvimento em saúde apresentaram menor incidência de crimes. Além disso, é válido destacar que a educação, mesmo tendo importância na literatura abordada, não pode ser explorada em função da sua não significância estatística nos modelos estudados. Porém, por apresentar sinais negativos nas análises de regressões realizadas, estão coerentes com a literatura, pois a falta de investimentos e de educação da população tende a potencializar aspectos da criminalidade.

Por fim, quando discutidas as possíveis diferenças geográficas na prática de crimes, é válido destacar a maior incidência de crimes na região Nordeste do estado. Resultado que se justifica por ser essa a região com maiores níveis de renda e com grandes aglomerações urbanas, aspectos que elevam a propensão à prática criminosa.

Diante das evidências encontradas, o presente trabalho apresenta como limitações a não consideração de outras questões na composição dos modelos, a falta da noção temporal e não apresentação dos resultados de criminalidade para cada município. Além disso, ressalta-se o reduzido número de informações. Outro ponto a ser destacado é que os resultados ficam limitados à amostra e aos métodos escolhidos.

A partir disso, para futuros estudos, sugere-se ampliar o modelo aplicado e utilizar-se de outras metodologias a fim de avaliar aspectos da criminalidade em cada município, caso da utilização dos métodos de Análise Envoltória de Dados (DEA) e da construção de índices. Outro ponto a ser destacado para estudos futuros é verificar a evolução da criminalidade no decorrer de um período de tempo a fim de que seja acompanhada a sua evolução. Ademais, recomenda-se para estudos futuros explorar a criminalidade com diversos outros aspectos a fim de verificar quais são as suas causas e quais as consequências a fim sejam comparados com os resultados desse estudo. 


\section{REFERÊNCIAS}

ALONSO, J. A. F. O cenário regional gaúcho nos anos 90: convergência ou mais desigualdade? Indicadores Econômicos FEE, Porto Alegre, v.31, p.97-118, 2003.

BALTAGI, B. H. Econometric Analysis of Panel Data. 3 ed. England: John Wiley \& Sons, 2005.

BARCELLOS, O.; PEREZ, R. T. A dinâmica da criminalidade brasileira entre a exclusão social e o crescimento econômico. Perspectiva Econômica, v. 5, n. 2, p. 92-112, 2009.

BATELLA, W. B.; DINIZ, A. M. A. Análise espacial dos condicionantes da criminalidade violenta no estado de Minas Gerais. Sociedade \& Natureza, Uberlândia, v. 22, n. 1, p. 151163,2010 .

BATELLA, W. B.; DINIZ, A. M. A.; TEIXEIRA, A. P. Explorando os determinantes da geografia do crime nas cidades médias mineiras. Revista de Biologia e Ciências da Terra, v. 8, n. 1, p. 21-31, 2008.

BEATO FILHO, C. C. Determinantes da Criminalidade em Minas Gerais. Revista Brasileira de Ciências Sociais, São Paulo, v. 13, n. 37, p. 74-89, 1998.

BECKER, G. S. Crime and punishment: an economic approach. Journal of Political Economy, Los Angeles, v. 76, n. 1, p. 1-50, 1968.

BRICEÑO-LEÓN, R. La nueva violencia urbana de America Latina. Sociologias, Porto Alegre, a. 4, n. 8, p. 34-51, 2002.

CERQUEIRA, D.; LOBÃO, W.; CARVALHO, A. X. O jogo dos sete mitos e a miséria da segurança pública no Brasil. Texto para Discussão, IPEA, Rio de Janeiro, n. 1144, 2005.

GORDON, M. B. et al. Crime and punishment: the economic burden of impunity. The European Physical Journal B, v. 68, p. 133-144, 2009.

GREENE, W. H. Econometric analysis.6 ed. New Jersey: Prentice Hall, 2008.

FARIAS, C. A.; FIGUEIREDO, A. M.; LIMA, J. E. de. Dependência Espacial e Análise de Agrupamento de Municípios para Diferentes Tipos de Crime em Minas Gerais. Reuna, Belo Horizonte, v. 13, n. 3, p. 67-83, 2008.

FUNDAÇÃO ECONÔMICA E ESTATÍSTICA - FEE. FEE Dados. Disponível em:<http://www.fee.rs.gov.br/feedados/consulta/sel_modulo_pesquisa.asp>. Acesso em: 23.09.2014a.

FUNDAÇÃO ECONÔMICA E ESTATÍSTICA - FEE. Idese. Disponível em: $<$ http://www.fee.rs.gov.br/indicadores/indice-de-desenvolvimento-socioeconomico/>. Acesso em: 07.09.2014b. 
NASCIMENTO, J. S. et al. Estudo dos Determinantes do Crime de Homicídio no Município de Aracaju-SE. Revista Economia \& Gestão, v. 11, n. 25, p. 62-88, 2011.

OLIVEIRA, C. A. de. Análise espacial da criminalidade no Rio Grande do Sul. Revista de Economia, v. 34, n. 3, a. 32, p. 35-60, 2008.

OLIVEIRA, C. A. de. Criminalidade e o Tamanho das Cidades Brasileiras: Um enfoque da Economia do Crime. Texto para Discussão, CEPEAC, Passo Fundo, n. 14, 2005.

OLIVEIRA, C. A. de; MARQUES JÚNIOR, L. dos S. Uma Análise da Criminalidade na Região do Corede Produção a partir da Teoria Econômica do Crime (1997-2005). Análise, Porto Alegre, v. 20, n. 2, p. 65-83, 2009.

PEREIRA, R.; FERNANDEZ, J. C.; A criminalidade na região policial da grande São Paulo sob a ótica da economia do crime. Revista Econômica do Nordeste, v. 31, n. especial, p. 898-918, 2000.

PROGRESSO SOCIAL. Índice de Progresso Social dos Países 2014. Disponível em: Acesso em: <http://www.progressosocial.org.br/> 10.09.2016.

RESENDE, J. P. de; ANDRADE, M. V. Crime Social, Castigo Social: Desigualdade de Renda e Taxas de Criminalidade nos Grandes Municípios Brasileiros. Estudos Econômicos, São Paulo, v. 41, n. 1, p. 173-195, 2011.

ROLNIK, R. Exclusão territorial e violência. São Paulo em perspectiva, v. 13, n. 4, p. 100$111,1999$.

SCALCO, P. R.; AMORIN, A. L.; GOMES, A. P. Eficiência técnica da Polícia Militar em Minas Gerais. Nova Economia, Belo Horizonte, v. 22, n. 1, p. 165-190, 2012.

SECRETARIA DE SEGURANÇA PÚBLICA DO RIO GRANDE DO SUL - SSP-RS. (2014). Indicadores Criminais SSP de 2002 a 2012. Disponível em: <http://www.ssp.rs.gov.br/?model=conteudo\&menu=191>. Acesso em: 23.09.2014.

SHIKIDA, P. F. A.; OLIVEIRA, H. V. N. Crimes violentos e desenvolvimento socioeconômico: um estudo sobre a mesorregião Oeste do Paraná. Revista Brasileira de Gestão e Desenvolvimento Regional, Taubaté, v. 8, n. 3, p. 99-114, 2012.

SILVA, B. F. A. Coesão Social, Desordem Percebida e Vitimização em Belo Horizonte. 2004. Dissertação (Mestrado em Sociologia) - Universidade Federal de Minas Gerais. Belo Horizonte, MG.

SILVA, M. A. e; MARION FILHO, P. J.; CORONEL, D. A. Análise das desigualdades entre os COREDES no período de 1990 a 2003: origem e evolução. Perspectiva Econômica, São Leopoldo, v. 3, n. 1, p. 62-81, 2007.

SIMON, H. A. Comportamento administrativo: estudo dos processos decisórios nas organizações administrativas. Rio de Janeiro: Fundação Getúlio Vargas, 1965. 
SOARES, T. C.; ZABOT, U. C.; RIBEIRO, G. M. Índice geral de criminalidade: uma abordagem a partir da análise envoltória de dados para os municípios catarinenses. Leituras de Economia Política, Campinas, v. 19, p. 89-109, 2011.

TODARO, M. P.; SMITH, S. C. Economic Development. Tenth Edition, Addison -Wesley, Boston, 2009.

VIAPIANA, L. T. Economia do Crime: uma explicação para a formação do criminoso. 1 ed. Porto Alegre: Editora AGE, 2006. 